\title{
Sexually Transmitted Diseases Among College Students in Sierra Leone: A Life Course Ecological Analysis
}

\author{
Eusebius Small ${ }^{1}$ D $\cdot$ Youn Kyoung $\mathrm{Kim}^{2} \cdot$ Mansoo Yu $^{3}$
}

Accepted: 5 December 2020 / Published online: 8 January 2021

(c) The Author(s), under exclusive licence to Springer Science+Business Media, LLC part of Springer Nature 2021

\begin{abstract}
Applying life course theory, this study examined the direct and indirect effects of adverse childhood experiences (ACEs) on the risk of contracting sexually transmitted diseases (STDs), mediated by early sexual activity (first sexual experience before age 15), number of lifetime sex partners, and mental health problems. The link between ACEs and mental health on college students' sexual risk is still understudied. Using cross-sectional data from a sample of 327 college students in Sierra Leone, this study tested the hypothesized mediation model using structural equation modeling analysis. The results showed that ACEs significantly increased sexual risks. Specifically, ACEs increased the risk of early initiation of sexual activity and the number of lifetime sex partners, which in turn increased the risk of STDs. Furthermore, ACEs significantly predicted negative mental health and were significantly associated with an increased risk of STDs. Effective future intervention strategies should include health education programs to address the lifelong effects of ACEs and mental health treatment.
\end{abstract}

Keywords Adverse childhood experience $\cdot$ Sexually transmitted disease $\cdot$ Early sexual activity $\cdot$ Number of lifetime sex partners $\cdot$ Mental health

Eusebius Small

esmall@uta.edu

Youn Kyoung Kim

ykim@1su.edu

Mansoo Yu

yuma@missouri.edu

1 School of Social Work, University of Texas, Arlington, 211 S. Cooper St., Bldg. A, Arlington, TX 76019, USA

2 School of Social Work, Louisiana State University, 207 Huey P. Long Field House, Baton Rouge, LA 70803, USA

3 School of Social Work, Department of Public Health, University of Missouri, 720 Clark Hall, Columbia, MO 65211, USA 


\section{Introduction}

Adolescents and young adults engage in risky behaviors such as unprotected sexual activity, sexting and problematic and risky internet use, use of illegal substance, and dangerous driving than any other age group (Centers for Disease Control and Prevention [CDC], 2018). The 2019 Sierra Leone Demographic and Health Survey (SLDHS) indicated high-risk sexual behaviors such as having multiple sexual partners, unprotected sex, and transactional sex among adolescents. In the United States, for example, despite educational efforts to provide teens with information about risky behavior, adolescents ages 15-24 account for half the 20 million new sexually transmitted diseases (STDs) annually, with incidences of gonorrhea, chlamydia, and syphilis exceeding 1.5 million among college students (Inside Higher Education 2016).

Extant research is silent on why STD cases are high among college students (CDC 2016), a growing body of brain research, however, reveals that adolescence is a stage of neurodevelopment affecting decision making (Steinberg 2008). These neurodevelopmental changes occur around the time of puberty, to impact the lateral prefrontal cortex (PFC) responsible for emotional maturity, self-regulation, and reward-seeking (Chambers et al. 2003). Other biological factors that may facilitate STD transmission among young women include the underdeveloped cervical cells. For example, cervical ectopy is associated with chlamydia trachomatis infection and HIV in young women (Kleppa et al. 2015). Adverse childhood experiences (ACEs) such as a history of conflicts and war, as is the case for Sierra Leone, or witnessing violence among household members may These neurodevelopmental changes occur around the time of puberty, to impact the lateral prefrontal cortex (PFC) responsible for emotional maturity, self-regulation and reward-seeking also affect sexual behaviors (Betancourt et al. (2011). Today's new media platforms create an information delivery pipeline of problematic and risky internet use that could facilitate sexual activities (Collins et al. 2011). Branley and Covey (2017) found a strong linkage between social media content and associated offline individual risky behaviors.

The impact of the environment on risky sexual behaviors has also been studied (DiClemente et al. 2005). Living in environments where abuse and trauma are prevalent (Jones et al. 2013; Littleton et al. 2007), substance misuse (Mandavia et al. 2016; Schäfera et al. 2017), or with individuals with untreated mental illnesses (Bahk et al. 2016; Dubé et al. 2016) may also heighten problem behaviors including risky sexual behaviors. Examined less often in the ecological systems literature is how time (or, in Bronfenbrenner's terms, "the chronosystem") impacts the association among the factors. In addition, life-course theory examines the longitudinal processes of human development, organized around four critical focal points: (1) historical time and place, given the idea that the social context of people's lives influences their opportunities as well as their challenges; (2) linked or interdependent experiences, based on the interconnected nature of individual lives and how social networks present both risk and resilience factors; (3) timing of life events, as it is assumed that the time when significant events 
occur in one's life will impact one's developmental trajectories; and (4) developmental risk and protection, as one life event or transition impacts subsequent events and transitions, and either may put it at risk or protect the life-course trajectory (Elder 1998; Elder et al. 2003; Giele and Elder 1998; Hutchison 2019). The life course theory has been applied to studies examining individuals' experiences with early initiation of sexual activities (EISA) (e.g., Haydon et al. 2014), multiple sexual partners (e.g., Rapp 2018), psychological harm (e.g., Thomeer et al. 2016), and sexually transmitted diseases (e.g., Lucke et al. 2013), which impact health trajectories.

Adolescents living in Sierra Leone face unique challenges. The civil war (1991-2002) and the Ebola crisis (2014-2016) are historical risky factors that have embroiled Sierra Leone. Exposure to adversity and conflict may be associated with higher odds of engagement in risky behaviors, including sexual risk behaviors (Jessor and Jessor 1977). Among individuals with a history of ACEs, risky sexual behaviors may represent their attempts to achieve intimate interpersonal relationships (CDC 2019; Noll et al. 2009). Further, the effects of war, conflicts, and poverty on Sierra Leone's health infrastructure cannot be underestimated. More than $60 \%$ of the population of Sierra Leone live below the United Nations' poverty line of US\$1 per day. A lack of adequate shelter, food, and other basic needs at minimum consumption levels disproportionately impact young people in Sierra Leone or sub-Saharan Africa (SSA) increasing disease risk. For example, about 14,000 people are infected with HIV, and 11,000 die from AIDS-related illnesses daily in SSA. To put this into context, approximately 6313 COVID-19 related deaths occurred worldwide on September 4, 2020 (Worldmeter 2020).

There are several reasons for examining college students and risk-taking in this context. First, although at greater vulnerability for STD infection, this population is assumed to be educated and knowledgeable about STDs (Subbarao and Akhilesh 2017). Second, despite the realities of the biological and cultural factors mentioned above, college students are assumed to be educated, resilient, and unaffected by the impact of ACEs (Kelifa et al. 2020). Third, Sierra Leone is a less developed country (LDC) that struggles to maintain a steady STD prevention and treatment campaign due to budget constraints. For example, in 2017, the AIDS Healthcare Foundation (AHF) gave Sierra Leone \$5 million to help the government step up its HIV and STD prevention efforts (AHF 2017). By comparison, the U.S. spends $\$ 15.6$ billion a year on adolescent sexual health programs (CDC 2018). Such scarcity of resources may be associated with a high STD burden in Sierra Leone and other SSA countries.

Very little research has examined interactions between multiple social-ecological factors concerning college students' sexual behavior, such as alcohol use and misuse, risky sexual behaviors, peer influence, and other macrolevel factors such as advertising and marketing (Sudhinaraset et al. 2016). Such research is needed to understand the mechanisms of sexual risk to inform intervention outcomes. The current study utilizes Bronfenbrenner's ecological systems perspective (1979) and life course perspective (Elder et al. 2003; Giele and Elder 1998) to assess ACEs' related sexual risks among college students in Sierra Leone. 


\section{Sexually Transmitted Diseases Among Students In Sierra Leone}

Results from the 2019 Sierra Leone Demographic and Health Survey (SLDHS) found that young females and males ages 15-24 who were never married have engaged in multiple sexual relationships in the previous 12 months. Among those surveyed, $80 \%$ of the females and $71 \%$ of the males reported having sexual relationships with people other than their partners. Teen pregnancy was high, at $65 \%$, during the 2016 Ebola crisis (CDC 2018). By comparison, the Department of Health's (2019) National Antenatal Sentinel HIV and Syphilis Prevalence Surveys of South Africa showed that $7 \%$ of young women ages 15-24 in South Africa were pregnant in 2017 (Department of Health [South Africa] 2019). According to the World Bank, Sierra Leone had the 13th highest rate of teenage pregnancy globally in 2017, with 113 births per 1000 adolescents, more than 10 times the rate in Europe (Peyton 2019). The high pregnancy rates in Sierra Leone are driven by low education, poverty, and abuse (Peyton 2019).

\section{Adverse Childhood Experiences, Mental Health, and Sexually Transmitted Diseases}

ACEs, including child abuse and trauma, have been implicated as predictors of sexual risk behaviors and related lifelong consequences (Senn and Carey 2010; Wilson et al. 2012). They are associated with high-risk sexual behavior, including early initiation of sexual activity (EISA), unprotected intercourse without a male or female condom, having multiple sex partners, or having a high-risk partner (one who has multiple sex partners or other risk factors; Bensley et al. 2000). Furthermore, childhood abuse interrupts a child's developmental stages, affecting learning, intimacy skills, dating, and developing one's identity or autonomy (Connolly and McIsaac 2009; Steinberg 2008). Toxic stress from ACEs can interfere with brain development, and people with increased exposure to ACEs may have associated pain-related psychological trauma, depressive episodes, and psychosocial impairment (Ege et al. 2015).

\section{Current Study}

Consistent with life course theory, which suggests that the times when significant life events occur impact one's developmental trajectories, we theorize that students exposed to childhood abuse or trauma have a higher likelihood of engaging in sexual risk behaviors compared with those who have not been exposed, controlling for other factors such as parenting style, gender, and home environment (Lucke et al. 2013; Haydon et al. 2014; Rapp 2018; Thomeer et al. 2016). The current study applies the concepts of life course theory to examine the relationship between ACEs and sexual risk. Therefore, we tested the following hypotheses: [HI] ACEs will be significantly associated with increases in risk of contracting STDs; [H2] ACEs will be significantly associated with early initiation of sexual activity (EISA), number of lifetime sex partners (NLSPs), and mental health problems (i.e., depression and anxiety); 
[H3] EISA, NLSPs, and mental health will be significantly associated with increases in risk of contracting STDs; [H4] EISA will mediate the association between ACEs and STDs; [H5] NLSPs will mediate the association between ACEs and STDs; [H6] Mental health will mediate the association between ACEs and STDs; [H7] NLSPs will mediate the association between ACEs and STDs via EISA; [H8] Mental health will mediate the association between ACEs and STDs via NLSP; [H9] Mental health will mediate the association between ACEs and STDs via EISA and NLSPs.

\section{Methods}

\section{Study Design and Sample}

This cross-sectional study involved a sample of 327 university students attending two colleges located in the southern and northern province of Sierra Leone between May and June of 2017. Approval of the study was granted by the first author's University Institutional Review Board and the Sierra Leone Office of Ethics and Scientific Review Committee in August of 2016 and May of 2017, respectively. A convenience sampling method was used to select the two universities based on proximity to the lead author and diversity in geography (southern and northern regions).

Students were recruited from a biology class and a liberal arts class in the respective regions. Students' instructors informed the students about the study prior to the commencement of the class. The purpose of the study, potential benefits, and risks were explained in detail by the lead author before admistering the survey, and all participants were subsequently provided with an informed consent form. Participation in the study was voluntary and anonymous, and refusal to participate did not affect the students' course grades. Participation was granted if the student was 18 years or older, enrolled at one of the two institutions, and could read and write in English. The lead author administered the survey during a normal class period. The survey took between 40 and $60 \mathrm{~min}$ to complete. Incentives to participate were provided in the form of a lottery draw, in which the winning ticket was selected from a range of numbers between 0-100. A winning ticket had a number in the form of a smiley face, with a sticker that indicated, "You are the winner of a USB stick." A non-winning number came with the following message: "Sorry, you were not lucky this time." Participants were informed that if they experienced any discomfort while answering the questions, they could stop and leave the room without consequences. Contact information for psychological help was also provided if ever needed.

\section{Measures}

\section{Exogenous Variable}

The Adverse Childhood Experiences International Questionnaire (ACE-IQ; WHO 2016) was used to measure respondents' experience of child abuse during the first 18 years of life. As shown in Table 1, the scale consists of 13 domains and 


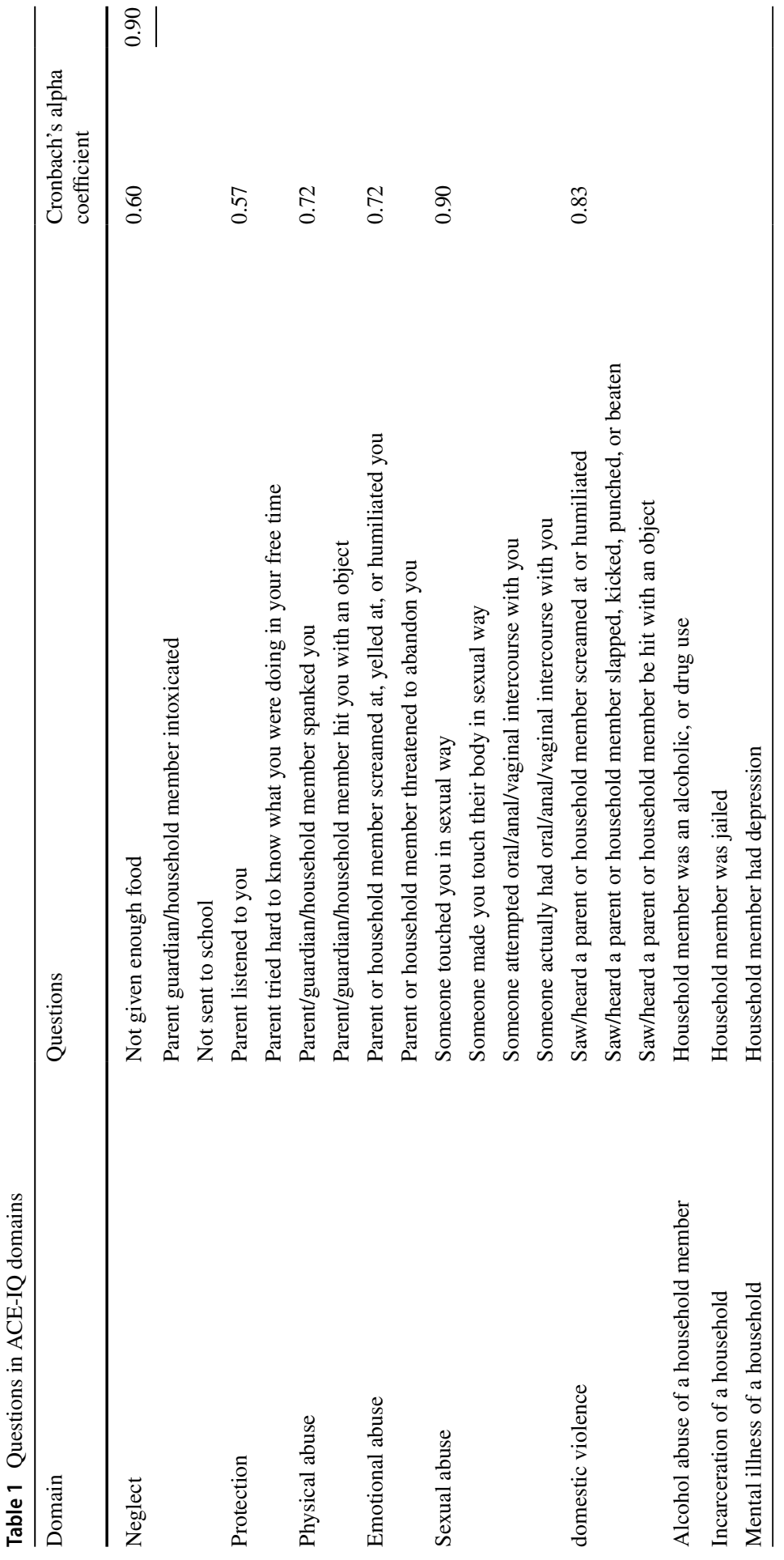




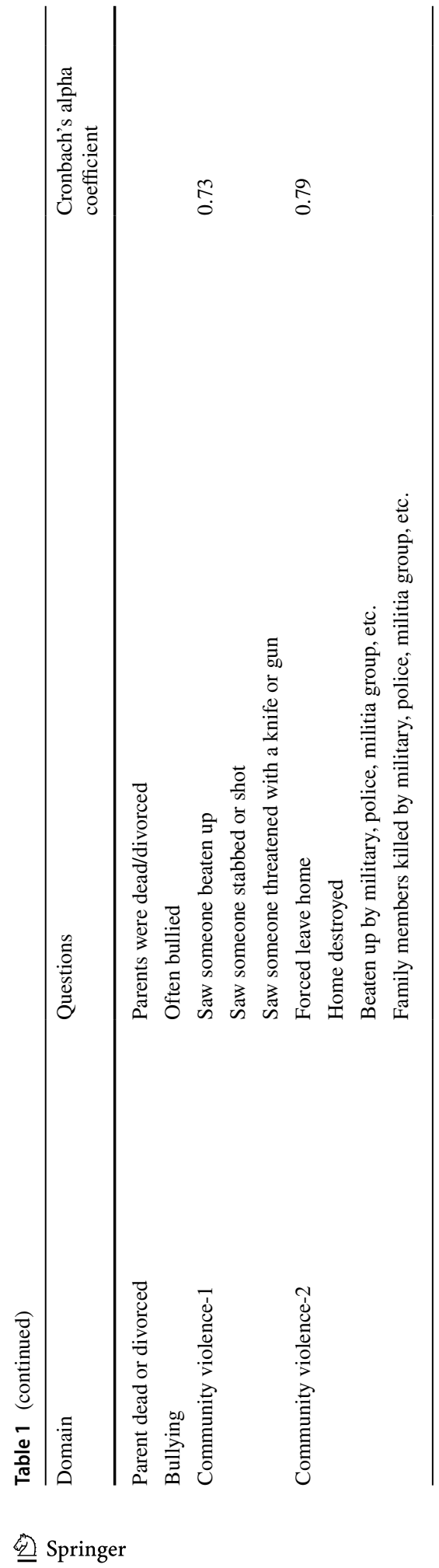


28 questions including three questions on neglect, two questions on protection, two questions on physical abuse, two questions on emotional abuse, four questions on sexual abuse, three questions on domestic violence, one question on alcohol abuse by a household member, one question on the incarceration of a household member, one question on mental illness in the household, one question on whether parents are dead or divorced, one question on bullying, three questions on community violence, and four questions on collective violence. The measurement uses a five-point Likert scale ranging from 1 (never) to 5 (always). Of 13 domains, eight domains have two items or more. Composite variables were created for these domains. Each composite score was divided by the number of items, and the mean of the composite score was used as an indicator for the analysisAs shown in Table 1, the Cronbach's alpha coefficients for these eight domains with two or more items ranged from 0.57 to 0.90 . The Cronbach's alpha coefficient for the whole scale was 0.90 , indicating strong internal consistency reliability.

\section{Endogenous Variable}

Information about STDs was obtained by respondents answering yes to the following question about STD: "Have you ever been diagnosed with or had any of the following STDs?" The response categories were none, Chlamydia, Gonorrhea, Syphilis, Herpes, HPV/Warts, HIV/AIDS, Hepatitis B, Hepatitis C, or other. We changed this categorical variable to a dichotomous variable $($ no $=0$, yes $=1)$ for any of the listed STD.

\section{Mediating Variables and Control Variable}

Three mediating variables were included in this study: (a) early initiation of sexual activity, (b) the number of lifetime sexual partners, and (c) mental health. First, early initiation of sexual activity was assessed as a continuous variable that measured the age when the respondent had sexual intercourse for the first time. For this study, we changed from the continuous variable to a dichotomous variable using the cut off age of 15 years old based on the study conducted by Brown and colleagues (2017). Having sexual intercourse before 15 years old was categorized as 1 and having sexual intercourse after 15 years old was categorized as 0 . Second, the number of lifetime sex partners was assessed as a count variable that measured the number of people the individual had ever had sex with. Lastly, mental health was conceptualized as anxiety and depression. We assessed participants' mental health problems by utilizing the Patient Health Questionnaire 9 (PHQ-9) and the Generalised Anxiety Disorder (GAD-7) questionnaire. The ultimate mental health variable was comprised of these two variables. The PHQ-9 was developed by Kroenke et al. (2001); it is a 9-item self-administered questionnaire for the assessment of the severity of symptoms of depression for patients undergoing clinical treatment. A sample question is, "In the last two weeks, how often have you been bothered by any of the following problems?" Respondents indicated the degree to which each statement was true on a four-point Likert scale, ranging from 0 (not at all) to 3 (nearly every day). PHQ-9 contained statements such as "little interest or pleasure in doing things" and "trouble falling or staying asleep, or sleeping too 
much." Scores have been organized on a scale of increasing severity of depression, ranging from 0 to 4 . For this research, the mean of the PHQ-9 became central to the analysis (see Table 3), having a Cronbach's alpha coefficient of 0.70 . The GAD-7 scale was used to measure anxiety. This 7-item scale, developed by Spitzer and colleagues (2006), is a self-administered questionnaire for the assessment of how frequently anxiety symptoms appear for patients receiving clinical treatment or participating in clinical research. The GAD-7 measurements range over a four-point Likert scale from 0 (not at all) to 3 (nearly every day). A multipart sample question is, "In the last two weeks, how often have you been bothered by the following problems: (1) not being able to stop or control worrying, and (2) feeling afraid as if something awful might happen." In this research, the analysis was undertaken using the mean for the GAD-7 (see Table 3). The Cronbach alpha for the GAD-7 was 0.82, which indicates strong relibility. Age was a control variable in this study.

\section{Data Analysis}

For the central analysis, Mplus 7.4 (Muthén and Muthén 2015) was used to conduct structural equation modeling (SEM), comprised of a measurement model and a structural path model. Westland (2010) suggests 10 per indicator in a path model as the minimum preferred sample size to use SEM to attain statistical stability. For this study, the sample size of 327 was adequate to test the SEM model with 9 indicators in the path model.

Confirmatory factor analysis (CFA) was used to test the measurement model before testing the structural path model. The measurement model was tested to determine whether the observed items employed for measuring the two latent variables (adverse childhood experience and mental health) operated as valid indicators for the constructs. The structural path model then underwent testing to assess the hypothesized conceptual model. The structural path model offers a description of how all the variables for the projected model are interrelated. This model also displays the direct and indirect effects of specific variables on certain other variables in the model. This research looks at the direct and indirect paths from adverse childhood experiences to STD infections through the mediators of early initiation of sexual activity, number of lifetime sex partners, and mental health.

\section{Results}

\section{Descriptive Information}

Table 2 includes the descriptive information of the sample. The sample of college students identified as $41.9 \%$ female and $58.1 \%$ male. The average age of the respondents was 24.33 , with a range of 18 to 56 years. $61.2 \%$ were from the southern university, and $38.8 \%$ from the northern region. The majority of the sample $(84.1 \%)$ were college freshmen, followed by college juniors $(6.4 \%)$, seniors $(4.6 \%)$, 
Table 2 Descriptive sample statistics $(\mathrm{N}=327)$

\begin{tabular}{|c|c|c|c|c|}
\hline Variable & $\%(n)$ & Mean & SD & Range \\
\hline \multicolumn{5}{|l|}{ Gender } \\
\hline Female & 41.9 (137) & & & \\
\hline Male & $58.1(190)$ & & & \\
\hline Age & & 24.33 & 5.66 & $18-56$ \\
\hline \multicolumn{5}{|l|}{ Region } \\
\hline North & $38.8(127)$ & & & \\
\hline South & $61.2(200)$ & & & \\
\hline \multicolumn{5}{|l|}{ Educational level } \\
\hline College freshman & $84.1(275)$ & & & \\
\hline College Sophomore & $3.1(10)$ & & & \\
\hline College Junior & $6.4(21)$ & & & \\
\hline College Senior & $4.6(15)$ & & & \\
\hline Master & $1.8(6)$ & & & \\
\hline \multicolumn{5}{|l|}{ Family’s income } \\
\hline Lower than average & $43.4(142)$ & & & \\
\hline Higher than average & $8.6(28)$ & & & \\
\hline Similar to the average family & $48.0(157)$ & & & \\
\hline \multicolumn{5}{|c|}{ Early initiation of sexual activity $(1$ st $\operatorname{Sex}<15)$} \\
\hline No & $92.4(302)$ & & & \\
\hline Yes & $7.6(25)$ & & & \\
\hline Number of lifetime sex partners & & 3.24 & 2.14 & $0-6$ \\
\hline \multicolumn{5}{|c|}{ Experience with sexually transmitted disease (STD) } \\
\hline No & $68.5(224)$ & & & \\
\hline Yes & $31.5(103)$ & & & \\
\hline
\end{tabular}

sophomore $(3.1 \%)$, and master's students $(1.8 \%)$. Because of the country context, sophomore satus may not have any association with age since it is not unusual for individuals to start college at an older age. More than $90 \%$ of the sample reported their family's income as lower than average or similar to the average family.

With respect to early initiation of sexual activity, $7.6 \%$ of the respondents reported they first had sex before age 15 . The average number of lifetime sex partners among respondents was 3.24 people, ranging from 1 to 6 people. Approximately one-third of the respondents reported they had experience with sexually transmitted infections. Table 3 describes the means and standard deviations of the variables in the SEM model.

\section{Measurement Model-CFA Results}

As shown in Table 4, the initial original model fit was inadequate. When estimating the factor loadings, five items (i.e., neglect, protection, incarceration of a house member, mental illness of a house member, and bullying) had a factor loading lower than 0.5. In contrast, all other indicators had a factor loading greater than 0.5 (see Table 5). According to Truong and Mccoll (2011), factor loadings should 
Table 3 Description of the variables $(\mathrm{N}=327)$

\begin{tabular}{|c|c|c|c|}
\hline Variable & Mean & SD & Range \\
\hline \multicolumn{4}{|l|}{ ACEs } \\
\hline Neglect & 1.71 & 0.94 & $1-5$ \\
\hline Protection & 3.33 & 0,99 & $1-5$ \\
\hline PA & 1.73 & 0.93 & $1-5$ \\
\hline EA & 1.89 & 0.96 & $1-5$ \\
\hline SA & 1.41 & 0.80 & $1-5$ \\
\hline DV & 2.05 & 1.02 & $1-5$ \\
\hline AAHM & 1.53 & 1.05 & $1-5$ \\
\hline $\mathrm{IH}$ & 1.39 & 0.96 & $1-5$ \\
\hline MI & 1.45 & 0.99 & $1-5$ \\
\hline PDD & 1.73 & 1.00 & $1-5$ \\
\hline B & 2.06 & 1.10 & $1-5$ \\
\hline CV_1 & 2.50 & 1.12 & $1-5$ \\
\hline CV_2 & 1.42 & 0.71 & $1-5$ \\
\hline \multicolumn{4}{|l|}{ Mental health } \\
\hline Depression & 1.81 & 0.53 & $1-3.3$ \\
\hline Anxiety & 1.75 & 0.66 & $1-4$ \\
\hline
\end{tabular}

ACEs $=$ adverse childhood experiences, $\mathrm{N}=$ neglect, $\mathrm{P}=$ protection, $\mathrm{PA}=$ physical abuse, $\mathrm{EA}=$ emotional abuse, $\mathrm{SA}=$ sexual abuse, $\mathrm{DV}=$ domestic violence, $\mathrm{AAHM}=$ alcohol abuse of a house member $(\mathrm{AAHM}), \mathrm{IH}=$ incarceration of a house member, $\mathrm{MI}=$ mental illness of a household, PDD = parents dead or divorced, $\mathrm{B}=$ bullying, CV_1 = community violence $\_1, C V \_2=$ collective violence $\_1$

\begin{tabular}{lrrllll}
\hline Model & $\chi^{2}(p)$ & $d f$ & AIC & CFI & TLI & RMEA \\
\hline Original model & $529.71 * * *$ & 118 & $14,623.46$ & 0.63 & 0.57 & 1.0 \\
Post-hoc model & $41.43 * * *$ & 22 & 6367.15 & 0.98 & 0.98 & 0.05 \\
\hline$* * *<.001$ & & & & & &
\end{tabular}

$* * *<.001$

Table 4 CFA model fit indices

be greater than 0.5 for better results. Therefore, the five items for ACEs were not included in the post hoc model. The reduced number of items based on the information of factor loadings and the incorporation of the error covariance resulted in an improvement in the model fit, as seen on Table 4. The TLI and CFI values were above 0.98 , suggesting an excellent fit of the data model. The RMSEA value of 0.05 met the criteria for a good model. Furthermore, the AIC values decreased from $14,623.46$ to 6368 in the desired direction. The final model fit of the measurement model was also improved by allowing several items to co-vary based on the information from the modified model fit indices (see Fig. 1). Also, the reliabilities of ACEs and mental health were assessed with composite reliability (CR). If the value of $\mathrm{CR}$ is higher than 0.7 , it is considered adequate. $\mathrm{CR}$ is calculated using the following formula: $\left.\mathrm{CR}=\left(\sum \mathrm{K}\right)^{2} /\left[\left(\sum \mathrm{K}\right)^{2}+\left(\sum 1-\mathrm{K}^{2}\right)\right]\right)(\mathrm{K}=$ factor loading of every 
Table 5 CFA results

\begin{tabular}{llllrll}
\hline Latent variable & Items & $\beta$ & S.E. & $\beta /$ S.E. & $p$ & $\begin{array}{l}\text { Com- } \\
\text { posite reli- } \\
\text { ability }\end{array}$ \\
\hline $\begin{array}{c}\text { Adverse childhood } \\
\text { experience (ACE) }\end{array}$ & PA & 0.788 & 0.033 & 23.894 & 0.000 & 0.84 \\
& EA & 0.776 & 0.044 & 17.503 & 0.000 & \\
& SA & 0.637 & 0.043 & 14.990 & 0.000 & \\
& DV & 0.682 & 0.038 & 17.835 & 0.000 & \\
& AAHM & 0.529 & 0.047 & 11.206 & 0.000 & \\
& PDD & 0.519 & 0.046 & 11.173 & 0.000 & \\
& CV-2 & 0.581 & 0.045 & 12.974 & 0.000 & \\
Mental health & Depression & 0.908 & 0.008 & 120.626 & 0.000 & 0.75 \\
& Anxiety & 0.633 & 0.039 & 16.287 & 0.000 & \\
\hline
\end{tabular}

$\mathrm{PA}=$ physical abuse, $\mathrm{EA}=$ emotional abuse, $\mathrm{SA}=$ sexual abuse, $\mathrm{DV}=$ domestic violence, $\mathrm{AAHM}=$ alcohol abuse of a house member, $\mathrm{PDD}=$ parents dead or divorced, $\mathrm{CV} \_2=$ Collective violence_2

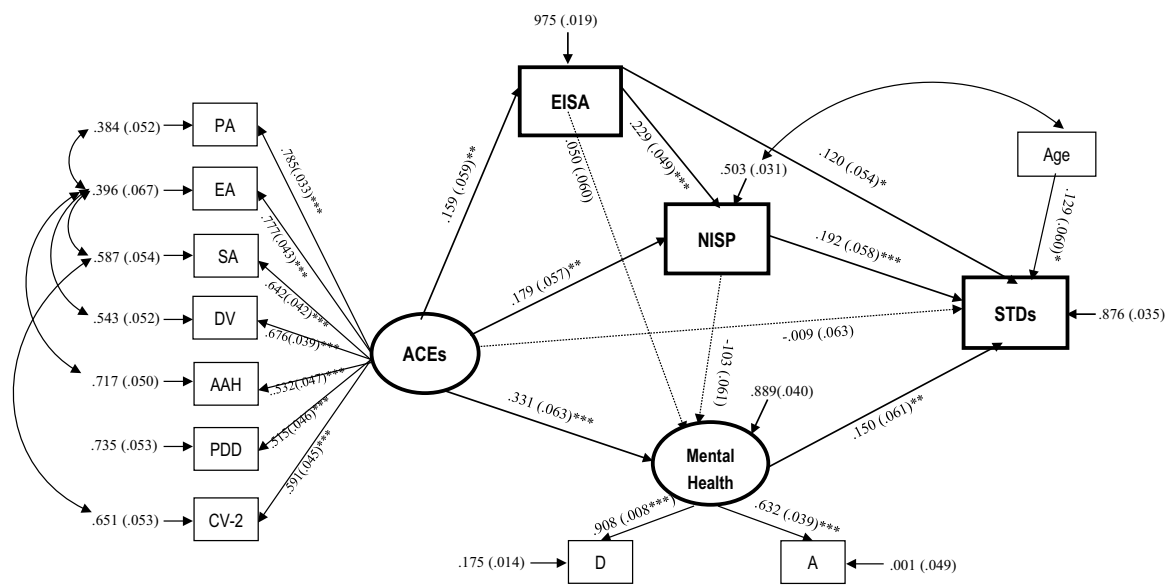

Fig. 1 Path results. Note $1 . *<.05, * *<.01, * * *<.001 ;$ ACEs $=$ adverse childhood experiences, $\mathrm{PA}=$ physical abuse, $\mathrm{EA}=$ emotional abuse, $\mathrm{SA}=$ sexual abuse, $\mathrm{DV}=$ domestic violence, $\mathrm{AAH}=$ alcohol abuse of a house member PDD $=$ Parents dead or divorced, CV-2 = collective violence_2, EISA = early initiation of sexual activity $(1$ st sex $<15)$, NISP $=$ number of lifetime sex partners, STDs $=$ sexually transmitted diseases, $\mathrm{D}=$ depression, $\mathrm{A}=$ anxiety, 2. Age was a control variable

item; Fornell and Larcker 1981). Overall, the composite reliability of each latent construct was greater than $0.7(\mathrm{ACEs}=0.84$, mental health $=0.75)$.

\section{Structural Model-Path Results}

To explore the direct and indirect effects of ACEs on STDs through the mediators of early initiation of sexual activity, the number of lifetime sex partners, and mental health, we tested the path model using SEM. The path results are shown in 
Table 6 Direct and indirect effects

\begin{tabular}{|c|c|c|c|c|}
\hline Path & $\beta$ & S.E & $\beta / S . E$ & $p$ \\
\hline \multicolumn{5}{|l|}{ Direct path } \\
\hline ACEs $\rightarrow$ EISA & 0.159 & 0.059 & 2.707 & 0.007 \\
\hline $\mathrm{ACEs} \rightarrow \mathrm{NLSP}$ & 0.179 & 0.057 & 3.114 & 0.002 \\
\hline $\mathrm{EISA} \rightarrow \mathrm{NLSP}$ & 0.229 & 0.049 & 4.676 & 0.000 \\
\hline $\mathrm{ACEs} \rightarrow \mathrm{MH}$ & 0.331 & 0.063 & 5.264 & 0.000 \\
\hline $\mathrm{ELSA} \rightarrow \mathrm{MH}$ & 0.050 & 0.060 & 0.833 & 0.405 \\
\hline $\mathrm{NLSP} \rightarrow \mathrm{MH}$ & -0.103 & 0.061 & -1.697 & 0.090 \\
\hline ACEs $\rightarrow$ STDs & -0.009 & 0.063 & -0.150 & 0.881 \\
\hline EISA $\rightarrow$ STDs & 0.120 & 0.054 & 2.224 & 0.026 \\
\hline $\mathrm{NLSP} \rightarrow \mathrm{STDs}$ & 0.192 & 0.058 & 3.309 & 0.001 \\
\hline $\mathrm{MH} \rightarrow$ STDs & 0.150 & 0.061 & 2.485 & 0.013 \\
\hline \multicolumn{5}{|l|}{ Indirect path } \\
\hline ACEs $\rightarrow$ EISA $\rightarrow$ STDs & 0.012 & 0.007 & 1.695 & 0.090 \\
\hline ACEs $\rightarrow$ NLSP $\rightarrow$ STDs & 0.022 & 0.010 & 2.217 & 0.027 \\
\hline $\mathrm{ACEs} \rightarrow \mathrm{MH} \rightarrow \mathrm{STDs}$ & 0.032 & 0.015 & 2.192 & 0.028 \\
\hline ACEs $\rightarrow$ EISA $\rightarrow$ MH $\rightarrow$ STDs & 0.001 & 0.001 & 0.767 & 0.443 \\
\hline ACEs $\rightarrow$ EISA $\rightarrow$ NLSP $\rightarrow$ STDs & 0.077 & 0.029 & 2.656 & 0.008 \\
\hline $\mathrm{ACEs} \rightarrow \mathrm{NLSP} \rightarrow \mathrm{MH} \rightarrow$ STDs & -0.002 & 0.001 & -1.242 & 0.214 \\
\hline $\mathrm{ACEs} \rightarrow \mathrm{EISA} \rightarrow \mathrm{NLSP} \rightarrow \mathrm{MH} \rightarrow$ STDs & 0.000 & 0.000 & -1.195 & 0.232 \\
\hline
\end{tabular}

ACEs $=$ adverse childhood experiences, EISA = early initiation of sexual activity $(1 \mathrm{st}$ sex $<15)$, $\mathrm{NISP}=$ number of lifetime sex partners, $\mathrm{MH}=$ mental health, $\mathrm{STD}=$ sexually transmitted diseases

Fig. 1. The structural path model had good model fit $\left[\chi^{2}(52)=89.64, p<0.001\right.$, $\mathrm{CFI}=0.97$, TLI $=0.95$, RMSEA $=0.05]$ as described in Fig. 1. The following direct and indirect path results partially supported our hypotheses.

\section{Direct Effects}

Ten direct paths were estimated, and the results showed that seven out of ten direct paths in the model were statistically significant (see Table 6). ACEs was significantly associated with early initiation of sexual activity $(\beta=0.159, p<0.01)$, the number of lifetime sex partners $(\beta=0.179, p<0.01)$, and mental health $(\beta=0.331$, $p<0.001)$. However, ACEs was not directly associated with STDs. Moreover, early initiation of sexual activity significantly increased the number of lifetime sex partners $(\beta=0.229, p<0.001)$ and increased the risk of STDs $(\beta=0.120, p<0.05)$, but it was not directly associated with mental health. Likewise, the number of lifetime sex partners increased the risk of STDs $(\beta=0.192, p<0.001)$, but it was not significantly associated with mental health. In addition, mental health significantly increased the risk of STDs $(\beta=0.150, p<0.05)$, like early initiation of sexual activity and the number of lifetime sex partners. 


\section{Indirect Effects}

The path results showed three significant mediating effects out of seven (see Table 6): (a) the number of lifetime sex partners significantly mediated the relationship between ACEs and STDs $(\beta=0.022, p<0.05)$; (b) mental health significantly mediated the relationship between ACEs and STDs $(\beta=0.032, p<0.05)$; and (c) early initiation of sexual activity as well as the number of lifetime sex partners significantly mediated the relationship between ACEs and STDs $(\beta=0.077, p<0.01)$. To be specific, the results demonstrated that ACEs significantly predicted the increased number of lifetime sex partners, which in turn led to an increased risk of STDs. Similarly, ACEs significantly predicted negative mental health, and then it was significantly associated with an increased risk of STDs. Lastly, ACEs increased the risk of early initiation of sexual activity and the number of lifetime sex partners, which in turn significantly increased the risk of STDs. However, the results did not support the hypothesis regarding the indirect mediating effects of early initiation of sexual activity, the number of lifetime sex partners, and mental health on the relationship between ACEs and STDs.

\section{Discussion}

STDs are one of the world's most common diseases. Our results showed that onethird of our respondents (32\%) have had an STD, with an average of three sexual partners. Although U.S. college students report having ever had, on average, more than 10 sexual partners (CollegeStats, n.d.), which exceeds our sample's self-report, sub-Saharan Africa carries a disproportionate burden of STDs, especially HIV, which accounts for more than $70 \%$ of the global burden of infection. We also found that about $8 \%$ of the respondents reported engaging in sex when they were younger than age 15. This prevalence is similar to the rate of other countries in Africa. For example, Mavhandu-Mudzusi and Asgedom (2016) found that about $6 \%$ of college students in Ethiopia began having sex before age 15. Research shows that adolsecnets who have a sexual debut before age 15 are less likely to use contracetion, including condoms that those who debut in the normative late age (CDC 2018). They may also develop cervical ectopy which is associated with STDs and HIV (Kleppa et al. 2015).

Our study extends the literature on adolescent risky sexual behaviors by examining direct and indirect effects of adverse childhood experiences (ACEs) on STD diagnosis through early initiation of sexual activity, number of sexual partners, and mental health problems. Our direct effects results are consistent with findings from previous studies that involved non-African college students, as well as in African settings (e.g., Ashenhurst et al. 2017; Hill et al. 2017). Early initiation of sexual activity, number of sexual partners, and mental health problems that involve anxiety and depression positively predicted STD diagnosis. The findings carry important implications for STD intervention research among college students, particularly those in Sierra Leone. 
First, sexual education is critical in informing young people about responsible choices in sexual relationships. However, it is not uncommon for college students to engage in sexual activity (e.g., Kebede et al. 2018). In our study, 9-in-10 individuals in the sample, consisting of more than $80 \%$ of freshmen, engaged in sexual activity. Other risks reported by our respondents reported early sexual debut (under 15 years), (7.6\%), have had STDs (31.5\%), and having sex with more than 3.24 sexual partners $(44.3 \%)$. Sexual education that teaches abstinence, postponing sexual intercourse, resisting unwanted and early sexual intercourse, and using contraception and practicing safer sex when adolescents become sexually active, is what universities can implement (Henok et al. 2015).

Communicating with the youth about the negative consequences of unprotected sex and providing them with health information that is basic and accurate will give them skills to protect themselves and others from HIV infection, other STDs, and pregnancy (Ashenhurst et al. 2017). We found that individual ACEs are associated with early-age sexual initiation, which also increased STD risk. The impact of ACEs, including physical, emotional, or sexual abuse, verbal humiliation that occurs while growing up with an abusive family member, can negatively affect neurobiology (Steinberg 2008). One way to deal with some effects from ACEs is to learn to build one's self-efficacy by seeking the right kinds of relationships. For example, finding people who are supportive and provide positive interactions with others, which can forge strong social ties that build confidence. Without positive reinforcement, individuals may not have the confidence to refuse unprotected or unwanted sex. In a study with a sample of college students in Ghana (Asante et al. 2016), students with higher self-efficacy levels for condom use were likely to use condoms. In helping female students develop self-efficacy, programs should consider genderpower inequality issues because Sierra Leone's Gender Inequality Index ranked 150 out of 189 in 2017 (United Nations Development Programme 2018).

In addition, based on our finding that the path from mental health problems to diagnosis of STDs is significant, screening for mental health problems, such as anxiety and depression, should be integrated into the assessment and treatment of STDs. It is important that students treat their mental health issues while screening for and treating STDs. Accordingly, it is recommended that training programs for healthcare professionals include mental health screening tools and resources for referral of STD students with mental health problems. Importantly, service providers need to understand that these students are likely to experience fear, shame, and stigma about STDs that may affect appropriate screening and treatment (Fortenberry et al. 2002).

Our study highlights that the associations between ACEs and diagnoses of STDs were significantly mediated by early initiation of sexual activity, number of sexual partners, and mental health problems. These findings are consistent with several previous studies' findings that compared with individuals who have no ACEs, individuals with ACEs are at increased risk of mental health problems, such as depression and anxiety (Hughes et al. 2017; Kim 2017; Merrick et al. 2017; Rehan et al. 2017). In addition, exposure to ACEs, including emotional abuse, physical abuse, sexual abuse, and parental incarceration, is associated with risky sexual outcomes including multiple sexual partners and contracting STDs (London et al. 2017). Service providers should carefully consider how early ACEs may exacerbate the risk 
of risky sexual behaviors and mental health problems, which are, in turn, associated with diagnoses of STDs. It is important to understand that exposure to ACEs has a lasting impact on risky sexual behaviors, mental and physical health. Notably, ACE screening and intervention, along with early education for sexual activity and screening for mental health problems, may be useful in addressing STDs among college students. For example, young men in Tanzania are less likely to use condoms if they have mental health problems such as depression and anxiety (Hill et al. 2017). It is important to note that exposure to the decade-long civil war in Sierra Leone negatively affected individual mental health. Although our students may not have experienced war themselves first hand, most reported post childhood adversity through ACEs. Access to mental health care providers is a big challenge because of a dramatic shortage in such health care professionals (WHO n.d.). In a country where physician density (per 1000) is 0.024 , (WHO n.d.). having adequate mental health care is almost inconceivable. Mental health trainings for various levels of service providers (e.g., social workers, community health workers, and nurses) could help address this mental health care provider shartages (WHO n.d.).

This study should be interpreted within several limitations. First, no causal relationships can be determined because of the cross-sectional study design. For example, the link between mental health problems and diagnosis of STDs can be reversed. In other words, college students can feel depressed or anxious after getting an STD. However, as mentioned above, we found more evidence of the path from ACEs to mental health problems, and the path from mental health problems to the acquisition of STDs. Second, recall bias can exist in the measures, such as ACEs, as the events happened during childhood. Third, underreporting can exist because both ACEs and sexual activity are sensitive subjects. College students tend to underreport their ACEs, onset age of sexual activity, number of sexual partners, and diagnoses of STDs. Fourth, the ACE-IQ, PHQ-9, and GAD-7 measures in this study have not been validated with college students in the sub-Saharan Africa. When conducting future research, it may be helpful to use measures that can be validated with African college students. Fifth, the data do not include some important information such as self-efficacy and use of certain contraceptive methods, however, students were asked whether they used condoms as away to protect themselves against STDs. Lastly, we used convenience sampling to collect data from only two colleges in Sierra Leon. Thus, the results are not generalizable to students in other colleges, or those individuals who are not attending a college in the country. These study limitations link to implications for future research. Future studies should utilize a longitudinal study design for causality, recruit other college students and college-aged individuals who are not attending a college using probability sampling for generalizability, and test additional predictors of diagnoses of STDs, such as self-efficacy and use of contraceptive methods, to strengthen our theoretical model. A nother possible limition of the study is social desirability, especially given that the survey was completed in class around peers. They could have been less likely to disclose certain information given the nature of the topic.

Regardless of any limitations, this study strengthens the ecological model by providing evidence on the chronosystem of the ecological model. Unlike previous studies, our study uniquely examined the mediating roles of early initiation of sexual 
activity, number of sexual partners, and mental health problems on the link between ACEs and STDs in a sample of college students in Sierra Leon. As mentioned, more than $30 \%$ of our study respondents reported experiencing an STD. It is important to understand the direct and indirect associations between ACEs and STDs and their joint associations with mental health problems and risky sexual behaviors among college students in Sierra Leon. It is also important to support continued efforts to design more effective intervention and health education programs for college students with STDs by addressing the lifelong effects of ACEs on risky sexual behaviors and mental health problems.

Funding No funding to report.

\section{Compliance with Ethical Standards}

Conflict of interest We do not have any conflict of interest.

Ethical Approval Our work was approved by the respective Institutional Review Board.

Ethical Standards We declare compliance with all ethical standards of disclosure, and informed consent.

Informed Consent All participants voluntarily provided with informed consent.

\section{References}

AIDS Healthcare Foundation. (2017). Sierra Leone awarded five million free condoms from AHF condom bank. Retrieved February 3, 2020 from https://www.aidshealth.org/2017/08/sierra-leone-awarded5-million-free-condoms-ahf-condom-bank/.

Asante, K. O., Osafo, J., \& Doku, P. N. (2016). The role of condom use self-efficacy on intended and actual condom use among university students in Ghana. Journal of Community Health, 41(1), 97-104.

Ashenhurst, J. R., Wilhite, E. R., Harden, K. P., \& Fromme, K. (2017). Number of sexual partners and relationship status are associated with unprotected sex across emerging adulthood. Archives of Sexual Behavior, 46(2), 419-432.

Bahk, Y. C., Jang, S. K., Choi, K. H., \& Lee, S. H. (2016). The Relationship between childhood trauma and suicidal ideation: Role of maltreatment and potential mediators. Psychiatry Investigation, 14(1), 37-43.

Bensley, L., VanEenwyk, J., \& Simmons, K. (2000). Self-reported childhood sexual and physical abuse and adult HIV-risk behaviors and heavy drinking. American Journal of Preventive Medicine, 18, 151-158.

Betancourt, T. S., Borisova, I. I., de la Soudière, M., \& Williamson, J. (2011). Sierra Leone's child soldiers: War exposures and mental health problems by gender. The Journal of Adolescent Health: Official Publication of the Society for Adolescent Medicine, 49(1), 21-28. https://doi.org/10.1016/j. jadohealth.2010.09.021.

Branley, B., \& Covey, J. (2017). Is exposure to online content depicting risky behavior related to viewers' own risky behavior offline? Computers in Human Behavior, 75(2017), 283-287.

Centers for Disease Control and Prevention. (2016). 2016 STD prevention conference highlights. Retrieved July 18, 2019 from https://www.cdc.gov/stdconference/2016/highlights/adol.htm. 
Centers for Disease Control and Prevention. (2018). Sexually transmitted disease surveillance 2017: STDs in adolescents and young adults. Retrieved July 16, 2019 from https://www.cdc.gov/std/stats 17/adolescents.htm.

Centers for Disease Control and Prevention. (2019). Preventing adverse childhood experiences. Retrieved February 3, 2020 from https://www.cdc.gov/violenceprevention/childabuseandneglect/aces/fastfact. html?CDC_AA_refVal=https $\% 3 \mathrm{~A} \% 2 \mathrm{~F} \% 2 \mathrm{Fwww} . \mathrm{cdc}$.gov $\% 2$ Fviolenceprevention $\% 2 \mathrm{Fchildabuseand}$ neglect $\% 2$ Facestudy $\% 2$ Faboutace.html.

Chambers, R., Taylor, J., \& Potenza, M. (2003). Developmental neurocircuitry of motivation in adolescence: A critical period of addiction vulnerability. American Journal of Psychiatry, 160, 1041-1052.

CollegeStats. (n.d). College sexual exposure. Retrieved July 22, 2019 from https://collegestats.org/explo re/collegiate-sexual-exposure/.

Collins, R. L., Martino, S. C., \& ShawRand, R. (2011). Influence of new media on adolescent sexual health: Evidence and opportunities working paper. Retrieved August, 20, 2019 from http://aspe.hhs. gov/hsp/11/AdolescentSexualActivity/NewMediaLitRev.

Connolly, J. A., \& McIsaac, C. (2009). Romantic relationships in adolescence. In R. Lerner \& L. Steinberg (Eds.), Handbook of adolescent psychology (3rd ed., pp. 101-151). Hoboken, NJ: Wiley.

Department of Health. (2019). National antenatal sentinel HIV and syphilis prevalence surveys 2017. Pretoria: DoH.

Department of Health (South Africa). (2019). South Africa National Antenatal Sentinel HIV and Syphilis Prevalence Survey 2000-present. Retrieved December 21, 2020, from http://ghdx.healthdata.org/ series/south-africa-national-antenatalsentinel-hiv-and-syphilis-prevalence-survey.

DiClemente, R. J., Salazar, L. F., Crosby, R.A., \& Rosenthal, S. L. (2005). Prevention and control of sexually transmitted infections among adolescents: the importance of a socio-ecological perspective- $\mathrm{a}$ commentary. Public Health, 119(9), 825-836.

Dubé, S., Lavoie, F., Blais, M., \& Hébert, M. (2016). Consequences of casual sex relationships and experiences on adolescents' psychological well-being: A prospective study. Journal of Sex Research, 54(8), 1006-1017.

Ege, M. A., Messias, E., Thapa, P., \& Krain, L. P. (2015). Adverse childhood experiences and geriatric depression: Results from 201 BRFSS. American Journal of Geriatric Psychiatry, 23(1), 110-114.

Elder, G. H., Jr. (1998). The life course as developmental theory. Child Development, 69(1), 1-12.

Elder, G. H. Jr., Johnson, M. K., \& Crosnoe, R. (2003). The emergence and development of life course theory. In J. T. Mortimer \& M. J. Shanahan (Eds.), The handbook of the life course (pp. 3-19) New York: Kluwer Academic/Plenum Publisher.

Fornell, C., \& Larcker, D. F. (1981). Evaluating structural equation models with unobservable variables and measurement error. Journal of Marketing Research, 18, 39-50.

Fortenberry, J. D., McFarlane, M., Bleakley, A., Bull, S., Fishbein, M., Grimley, D. M., et al. (2002). Relationships of stigma and shame to gonorrhea and HIV screening. American Journal of Public Health, 92(3), 378-381. https://doi.org/10.2105/Ajph.92.3.378.

Giele, J. Z., \& Elder, G. H. (1998). Life course research: Development of a field. In J. Z. Giele \& G. H. Elder, (Eds.), Methods of life course research: Qualitative and quantitative approaches (pp. 264294). Thousand Oaks, CA: Sage.

Haydon, A. A., Cheng, M. M., Herring, A. H., McRee, A. L., \& Halpern, C. T. (2014). Prevalence and predictors of sexual inexperience in adulthood. Archives of Sexual Behavior, 43(2), 221-230.

Henok, A., Kassa, A., Lenda, A., Nibret, A., \& Lamaro, T. (2015). Knowledge, attitude and practice of risky sexual behavior and condom utilization among regular students of Mizan-Tepi university, South West Ethiopia. Journal of Child and Adolescent Behavior. https://doi.org/10.4172/23754494.1000244.

Hill, L. M., Maman, S., Kilonzo, M. N., \& Kajula, L. J. (2017). Anxiety and depression strongly associated with sexual risk behaviors among networks of young men in Dar es Salaam, Tanzania. ADIS Care-Psychological and Socio-Medical Aspects of AIDS/HIV, 29(2), 252-258.

Hughes, K., Bellis, M. A., Hardcastle, K. A., Sethi, D., Butchart, A., Mikton, C., et al. (2017). The effect of multiple adverse childhood experiences on health: A systematic review and meta-analysis. Lancet Public Health, 2(8), E356-E366.

Hutchison, E. D. (2019). Dimensions of human behavior: The changing life course (6th ed.). Thousand Oaks, CA: SAGE.

Inside Higher Ed (2016). Colleges Vs. STDs. Retrieved July 19, 2020 from https://www.insidehighered. com/news/2016/11/03/cdc-finds-sharpgrowth-stds-college-age-population 
Jessor, R., \& Jessor, S. L. (1977). Problem behavior and psychosocial development: A longitudinal study of youth. New York: Academic Press.

Jones, D. J., Lewis, T., Litrownik, A., Thompson, R., Proctor, L. J., Isbell, P., et al. (2013). Linking childhood sexual abuse and early adolescent risk behavior: The intervening role of internalizing and externalizing problems. Journal of Abnormal Child Psychology, 41(1), 139-150.

Kebede, A., Molla, B., \& Gerensea, H. (2018). Assessment of risky sexual behavior and practice among Aksum University students, Shire Campus, Shire Town, Tigray, Ethiopia, 2017. BMC Research Notes, 11(88), 1-6.

Kelifa, M. O., Yang, Y., Carly, H., \& Wang, P. (2020). How adverse childhood experiences relate to subjective wellbeing in college students: The role of resilience and depression. Journal of Happiness Studies. https://doi.org/10.1007/s10902-020-00308-7.

Kim, Y. H. (2017). Associations of adverse childhood experiences with depression and alcohol abuse among Korean college students. Child Abuse and Neglect, 67, 338-348.

Kleppa, E., Holmen, S. D., Lillebø, K., Kjetland, E. F., Gundersen, S. G., Taylor, M., et al. (2015). Cervical ectopy: Associations with sexually transmitted infections and HIV. A cross-sectional study of high school students in rural South Africa. Sexually Transmitted Infections, 91(2), 124-129. https:// doi.org/10.1136/sextrans-2014-051674.

Kroenke, K., Spitzer, R. L., \& Williams, J. B. (2001). The PHQ-9: validity of a brief depression severity measure. Journal of general internal medicine, 16(9), 606-613. https://doi.org/10.104 6/j.1525-1497.2001.016009606.x.

Littleton, H., Breitkopf, C. R., \& Berenson, A. (2007). Sexual and physical abuse history and adult sexual risk behaviors: Relationships among women and potential mediators. Child Abuse and Neglect, 31(7), 757-768.

London, S., Quinn, K., Scheidell, J. D., Frueh, B. C., \& Khan, M. R. (2017). Adverse experiences in childhood and sexually transmitted infection risk from adolescence into adulthood. Sexually Transmitted Diseases, 44(9), 524-532.

Lucke, J., Herbert, D., Watson, M., \& Loxton, D. (2013). Predictors of sexually transmitted infection in Australian women: Evidence from the Australian longitudinal study on women's health. Archives of Sexual Behavior, 42(2), 237-246.

Mandavia, A., Robinson, G. G., Bradley, B., Ressler, K. J., \& Powers, A. (2016). Exposure to childhood abuse and later substance use: Indirect effects of emotion dysregulation and exposure to trauma. Journal of Traumatic Stress, 29(5), 422-429.

Mavhandu-Mudzusi, A. H., \& Asgedom, T. T. (2016). The prevalence of risky sexual behaviours amongst undergraduate students in Jigjiga University, Ethiopia. Health Sa Gesondheid, 21, 179-186.

Merrick, M. T., Ports, K. A., Ford, D. C., Afifi, T. O., Gershoff, E. T., \& Grogan-Kaylor, A. (2017). Unpacking the impact of adverse childhood experiences on adult mental health. Child Abuse and Neglect, 69, 10-19.

Muthén, L. K., \& Muthén, B. O. (2015). Mplus user's guide (8th ed.). Los Angeles, CA: Muthén \& Muthén.

Noll, J. G., Shenk, C. E., Barnes, J. E., \& Putnam, F. W. (2009). Childhood abuse, avatar choices, and other risk factors associated with internet-initiated victimization of adolescent girls. Pediatrics, 123(6), e1078-e1083.

Peyton, N. (2019). Just say no? Sierra Leone tests new ways to cut teen pregnancy. Retreived August 18, 2019 from https://www.reuters.com/article/us-leone-women-pregnancy/just-say-no-sierra-leone -tests-new-ways-to-cut-teen-pregnancy-idUSKCN1VQ281.

Rapp, I. (2018). Partnership formation in young and older age. Journal of Family Issues, 39(13), 3363-3390.

Rehan, W., Antfolk, J., Johansson, A., Jern, P., \& Santtila, P. (2017). Experiences of severe childhood maltreatment, depression, anxiety and alcohol abuse among adults in Finland. PLoS ONE, 12(6), $1-12$.

Schäfera, I., Pawils, S., Driessen, M., Härter, M., Hillemacher, T., Klein, M., et al. (2017). Understanding the role of childhood abuse and neglect as a cause and consequence of substance abuse: The German CANSAS network. European Journal of Psychotraumatology, 8(1304), 1-6.

Senn, T. E., \& Carey, M. P. (2010). Child maltreatment and women's adult sexual risk behavior: Childhood sexual abuse as a unique risk factor. Child Maltreatment, 15, 324-335.

Steinberg, L. (2008). A social neuroscience perspective on adolescent risktaking. Developmental Review, 28, 78-106. 
Subbarao, N. T., \& Akhilesh, A. (2017). Knowledge and attitude about sexually transmitted infections other than HIV among college students. Indian Journal of Sexually Transmitted Diseases and AIDS, $38(1), 10-14$

Sudhinaraset, M., Wigglesworth, C., \& Takeuchi, D. T. (2016). Social and cultural contexts of alcohol use: Influences in a social-ecological framework. Alcohol Research Current Reviews, 38(1), 35-45.

Thomeer, M., Reczek, C., \& Thomeer, M. B. (2016). Happiness and sexual minority status. Archives of Sexual Behavior, 45(7), 1745-1758.

Truong, Y., \& Mccoll, R. (2011). Intrinsic motivations, self-esteem, and luxury goods consumption. Journal of Retailing and Consumer Services, 18(6), 555-561.

United Nations Development Programme. (2018). Human development reports-table 5: Gender inequality index. Retrieved July 16, 2019 from http://hdr.undp.org/en/composite/GII.

Wilson, H. W., Woods, B. A., Emerson, E., \& Donenberg, G. R. (2012). Patterns of violence exposure and sexual risk in low-income, urban African American girls. Psychology of Violence, 2, 194-207.

World Health Organization. Adverse Childhood Experiences International Questionnaire (ACE-IQ). [Online] Retrieved in 2016 from http://www.who.int/violence_injury_prevention/violence/activities/ adverse_childhood_experiences/en/.

World Health Organization. Improving Access to Mental Health Services in Sierra Leone. [Online] Retrieved in 2019 from https://www.afro.who.int/news/improving-access-mental-health-servicessierra-leone.

Worldmeter. (2020). Corona Cases: 26,678,629. Retrieved October 15, 2020 from https://www.world ometers.info/coronavirus/?utm_campaign=homeAdUOA?Si.

Publisher's Note Springer Nature remains neutral with regard to jurisdictional claims in published maps and institutional affiliations. 